\title{
Novela colombiana entre 1990-2005: un enfoque desde el género negro*
}

Adriana Rodríguez Peña ${ }^{1}$

Universidad Central de Bogota

\section{Resumen}

Los estudios histórico-críticos sobre las novelas colombianas publicadas entre 1990 y 2005 caracterizan la narrativa del periodo desde dos grandes tendencias: novela de la ciudad o novela posmoderna. ¿Qué tan precisas son esas clasificaciones, dadas las particularidades y rasgos de este gran número de novelas que podrían relacionarse con el género negro? Este texto se propone mostrar las perspectivas teóricas, ideológicas e históricas de la novelas del periodo, que permiten hablar de una tendencia de la novela colombiana que está relacionada con el género negro en Colombia y en América Latina.

Palabras clave: género negro, condiciones, perspectivas, tendencia.

\section{Abstract}

The narrative of the period is characterized by the historical and critical studies about the Colombian novels published between 1990 and 2005, from two great tendencies: the city or postmodern novel. How precise are those classifications regarding the characteristics and features of this great amount of novels which could be related to the black genre? This text aims to show the theoretical, ideological and historical perspectives of the novels of the period, which give the possibility to speak about a tendency of the Colombian novel which is related to the black genre in Colombia and in Latin America.

Key Words: black genre; conditions; perspectives; tendency.

\footnotetext{
* El presente trabajo fue presentado en el Primer Coloquio Nacional de Historia de la Literatura Colombiana, realizado en Medellín, en abril de 2008, como parte de los resultados de la investigación sobre la Nueva Novela Negra en Colombia que se adelanta en la Universidad Central de Bogotá.

${ }^{1}$ Magíster en Literatura de la Universidad Javeriana. Docente del Departamento de Humanidades y Letras de la Universidad Central. Correo-e: walabo68@yahoo.com.
} 
No quiero empezar este texto haciendo alusión a las distintas formas de enunciación hechas por la crítica literaria sobre la novela colombiana de los últimos quince o veinte años. Voy a dejar de lado, por ahora, las categorizaciones y panoramas abstractos sobre la narrativa de este periodo. Voy a reflexionar, en primer lugar, sobre las condiciones literarias y sociales que hacen posible el cultivo del género negro en América Latina, y particularmente, en nuestro país. Con este enfoque busco vincular la narrativa al país cultural y político, es decir, a "las formas como las narrativas tratan de entender la cultura" (Silva, 2003: 88). En segundo lugar, analizaré algunas aproximaciones críticas al género como tendencia y su pertinencia a la hora de establecer un estado del campo de la novela colombiana.

Durante el siglo XX, la narrativa latinoamericana asimila las corrientes del relato policial en sus distintas tradiciones, desde la clásica inglesa, como la de Conan Doyle y Gilbert K. Chesterton, hasta la de tradición norteamericana, iniciada por Dashiel Hammett y Raymond Chandler. Estos últimos, al pretender innovar el género policial, aportaron los cimientos para edificar lo que hoy se conoce como "novela negra". En Latinoamérica, pese a las distintas denominaciones: "novela policíaca", "novela criminal", "neopolicíal", "novela negra", se puede afirmar que el término obedece a una renovación, a una actualización o superación del modelo de la novela negra norteamericana, gracias tanto a las condiciones literarias, como sociales, políticas y culturales de nuestros países.

Los estudios críticos coinciden en señalar la influencia de la narrativa norteamericana en Latinoamérica. Mempo Giardinelli, por ejemplo, sostiene que las coincidencias entre la novela policíaca en Estados Unidos y en América Latina (particularmente en Argentina y México), tienen que ver con el crimen y "la denuncia de la marginalidad, de la injusticia social en su más amplia concepción, de la represión que ejercen las autoridades, sean estas de una democracia liberalburguesa, como la norteamericana, o de las dictaduras cíclicas, como las latinoamericanas" (Giardinelli, 1980: 140). Sostiene este mismo autor que es en la relación con el poder y sus motivaciones donde se encuentran las diferencias fundamentales entre una y otra literatura.

La relación con el poder, en el caso norteamericano, se expresa en la confianza en el sistema; en América Latina las relaciones de poder están inscritas en la sumisión, el abuso y la injusticia. De ahí la falta de confianza y el deseo de cambio y rebelión contra éste. Esta es la razón fundamental para que gran parte de la crítica considere que el género en América Latina no es sólo una "forma de evasión o de entretenimiento sino un arma ideológica" (Giardinelli, 1980: 142). 
El género cobra importancia social durante el siglo XX, a lo largo de América Latina, primero en los círculos intelectuales, y luego como género popular. Así mismo, Giardinelli concluye que son los efectos de la injusta distribución, la crisis generalizada y las grandes diferencias sociales, los motivos fundamentales de cultivo del género en América Latina; mientras que para la narrativa norteamericana el foco de motivación está en el interés de los personajes por el dinero, la posesión, el lucro y la moral.

Sin embargo, es importante anotar que también coexisten circunstancias culturales que suscitan la lectura y posterior cultivo de esta forma de ficción narrativa en nuestro continente: la promoción de las ediciones de bolsillo ${ }^{2}$ que circularon durante los años $50 \mathrm{y}$ el gusto literario que despertaron en muchos lectores que, sumados a la realidad política y social como materia de escritura, configuran la atmósfera, el ambiente que hace posible el cultivo del género, particularmente en México y en Argentina, países con una próspera industria editorial.

En Colombia la lectura de novelas de aventuras, policíacas y de vaqueros se da con "las colecciones de cordel o de zapatería". Gracias a estas colecciones que se alquilan o intercambian en la zapatería, es donde el género comienza a difundirse y hace sus lectores a través de las colecciones Bruguera y Diana ${ }^{3}$. Sin embargo, no es por estas colecciones que se conoce a los grandes autores del género. Con las colecciones de Séptimo Círculo y Seix Barral ${ }^{4}$ algunos títulos circularon entre los integrantes del grupo "La Cueva", de García Márquez, y del grupo que se reunía alrededor de la revista Mito.

A partir de los años ochenta los lectores colombianos comienzan a abordar de manera más regular a los autores del género negro, gracias a la difusión de la colección de la serie "Novela Negra", publicada por Bruguera y distribuida por la librería Buchholz, inicialmente, y luego en supermercados. A través de esta colección el género negro

\footnotetext{
${ }^{2}$ Giardinelli muestra cómo la amplia difusión de ediciones de bolsillo, tanto en Argentina como en México, aseguraron la distribución y promoción del género policíaco y negro en América Latina. Algunas de estas ediciones son: en Argentina, Cobalto, Débora, Pandora, Linterna, Rastros, Teseo, "Serie naranja” y "El Séptimo Círculo (creado por Borges y Bioy Casares-1949); en México: Jaguar y Caimán.

${ }^{3}$ Es así como lo indica el escritor Roberto Rubiano Vargas, en entrevista inédita. En particular, se difundían las novelas de Marcial Lafuente Estefanía, en su momento uno de los autores más populares.

${ }^{4}$ Esta última colección en particular se hizo muy popular porque la superficie exterior de las hojas estaba pintada de negro.
} 
dejó de ser un asunto para iniciados y cayó en manos de toda clase de lectores, lo que obviamente abrió el camino para que los nuevos escritores se interesaran en el género.

Algunos de los estudios más relevantes coinciden en señalar las particularidades ideológicas, culturales, políticas y sociales de la novela negra, sus tendencias e intención. En términos generales, la novela negra es considerada como una forma de relato realista (Paz Balibrea, 2002: 113) en un campo de referencias compartidas: violencia, caos, decadencia (Rainov, 1978: 222), cuya intención fundamental refiere su carácter crítico y de denuncia social ante el poder (Pino, 2002: 1) .

Según Jacovkis (2006), Argentina es probablemente el país con mayor tradición en la narrativa policial, pues fue Jorge Luis Borges, en la década del cuarenta, quien popularizó y legitimó el género con la fundación de Séptimo Círculo, editorial especializada en la publicación de cuentos y artículos en los que se defiende el género policial de vertiente inglesa. A partir de los años sesenta, en el cono sur la corriente negra norteamericana se actualiza en una serie de obras que actúan como arma crítica ante la situación política del país en la narrativa de escritores como Rodolfo J. Walsh, Ricardo Piglia, Osvaldo Soriano, José Pablo Feinmann y Mempo Giardinelli.

En el caso de Chile, el género negro tuvo un fuerte control por parte de la dictadura, y es sólo a partir de los años ochenta que se empieza a difundir y consolidar en la industria editorial. Sus primeros cultivadores son Alberto Edwards, René Vergara y José María Nasal; en la década de los noventa el género se consolida con escritores como Roberto Ampuero, Luis Sepúlveda y Ramón Díaz Eterovic.

En México la producción literaria policial y negra también tiene una rica trayectoria. Antonio Helú creó la primera publicación referida a lo policial en el año de 1946: Selecciones policíacas y de misterio. Aunque, al parecer, la tendencia policial ha tenido mayor raigambre en autores como José Revueltas y Rafael Ramírez Heredia. En 1969 aparece la novela El complot Mongol, de Rafael Bernal, considerada como fundacional de la novela negra mexicana; posteriormente, Paco Ignacio Taibo II afirmaba haber encontrado en la novela negra

\footnotetext{
${ }^{5}$ Sobre esta idea puede revisarse Lo negro del policial, de Ricardo Piglia (2003); El relato policial en Argentina, de Jorge Rivera (1986); Asesinos de papel, de Jorge Lafforgue (1996); Breviario de la literatura policial en América Latina, de Stavans Ilán (1990); El género negro, de Mempo Giardinelli (1996); El género negro: su gestación anglosajona y colonización hispánica, de Cristian Brito (2000).
} 
un mundo que le permitía narrar los conflictos sociales a través de una historia policial: "Eso fue lo que me atrajo: estar en contacto con la problemática social y expresarlo a través del neopolicial latinoamericano"6.

Los inicios de la novela negra en Cuba se inscriben "en el género del espionaje, por ello acabó siendo un instrumento de propaganda del régimen" (Prada, 2005: 42). Dentro de esta tendencia se pueden mencionar autores como Luis Rogelio Nogueiras y Antonio Heras. Durante los últimos 15 años escritores como Leonardo Padura y Amir Valle se han consolidado como figuras emblemáticas del género negro en América Latina.

En el caso de Brasil es Rubem Fonseca quien traslada ese subgénero al campo del "gran arte". La narrativa de Fonseca es una de las más evolucionadas del género, en tanto que se adentra en el mundo de la ciudad latinoamericana, explora en técnicas de investigación, incorpora aspectos históricos y tipifica sicológicamente al criminal.

Puede concluirse de lo anterior que en nuestro continente, aunque el género surge por influencia de la literatura norteamericana, sus cultivadores encuentran muy pronto la manera de apropiarse del modelo y desarrollarlo desde la peculiaridad de nuestros países. La forma de la novela negra se fija en el individuo marcado por una ética social que lo define. Si bien en su origen puede responder a las expectativas y necesidades comerciales del medio editorial, es la condición social de los personajes, el juego permanente con su entorno -cómo se mueven, cómo piensan- lo que la hace específica y sella su orientación estética.

\section{Novela negra en Colombia}

Como señalé, en Colombia sólo a comienzos de los ochenta empieza a leerse masivamente a los autores del género negro. Los lectores son estudiantes universitarios, escritores que recién comienzan y profesores de literatura. Hasta ese momento lo que se conocía como policial en Colombia eran las novelas de Ian Fleming (la serie de James Bond, 007) y las "novelas de zapatería". Por eso no resulta extraño que, a principios de la década del setenta, surja en Cali un autor como Hernán Hoyos, que escribió parodias de novelas policíacas, como el caso de Cero cero ocho contra sancocho. Puede pensarse que en realidad los autores colombianos interesados en el género se incubaron durante la década del ochenta, ya que sólo una

\footnotetext{
${ }^{6}$ Entrevista: Paco Ignacio Taibo II, director de la Semana Negra, en Gijón..
} 
década después puede plantearse la consolidación de una tendencia, en términos de producción y difusión. De ahí la importancia analítica del género negro en Colombia entre 1990 y 2005.

El trabajo de Hubert Pöppel (2001) sobre La novela policíaca en Colombia es hasta ahora el único estudio sistemático que intenta establecer las raíces del género policial, y por extensión, del género negro ${ }^{7}$; según explica Pöppel, la falta de estudios rigurosos sobre el género policial y sus variantes hacen difícil la tarea de caracterización y sistematización del género negro en nuestro país. Por eso este estudio analiza el campo de la novela colombiana entre 1990-2005, para determinar los límites y alcances de la Nueva Novela Negra como tendencia, esto es, definir sus rasgos y la red de relaciones del contexto literario en el que se da. Hemos denominado Nueva Novel Negra al fenómeno literario que acontece en Colombia entre 1990 y 2005, para superar las nominaciones críticas que en el campo de la novela se han hecho (novela de ciudad, novela posmoderna, etc.). Desde nuestro punto de vista, la constitución del género como tendencia se inicia en los años noventa, por la confluencia de condiciones en el campo y disposiciones de los escritores como agentes del mismo.

Dentro del conjunto de condiciones que hacen posible la evolución del género están: el aumento de publicaciones, la diversidad de formas narrativas que buscan la elaboración artística de la realidad reciente (social, política, histórica) a través de un tratamiento estético del lenguaje y la actualización del género a través de distintas formas (parodia, metaficción, ironía, literariedad, verosimilitud). La introducción del género en nuestro país puede ser considerada como una cuestión de status, ya que creció entre los intelectuales como divertimento literario y estuvo encaminado a la plasmación en el relato de un complicado andamiaje de razonamiento y juego deductivo dispuesto a sorprender a los lectores eruditos. De ahí la afición por la parodia, entendida en su vocación de imitación, de juego con la forma.

Sobre esta última afirmación es necesario acotar algunos aspectos: en primer lugar, no puede afirmarse de manera definitiva que esta sea una condición generalizada, pero sí una particularidad presente en muchas de las obras que pueden ser consideradas como género negro. Por otra parte, esta condición de burla, de ironía con el lenguaje sobre el lenguaje y sobre la construcción de la realidad, puede ser entendida como un mecanismo de resistencia, una salida

\footnotetext{
${ }^{7}$ Pöppel utiliza el termino de policial y negro pera definir una ampliagama de subgéneros (novela policial-policíaca, novela criminal, novela detectivesca-novela negra).
} 
ante la anomia que gobierna el mundo social; pero también como un mecanismo de elaboración simbólico del dolor ante la violencia indiscriminada y la barbarie inusitada, ante la crisis social y política que ha vivido el país a lo largo de su historia. Ante todo, como una búsqueda estética frente al recrudecimiento de la ignominia, la ausencia de Estado y la falta de credibilidad en las instituciones que en la década del ochenta tuvo su renglón aparte y dio lugar a la exploración en el género policial negro como posible vía de escape.

Lo anterior lleva a establecer las condiciones específicas que hacen posible el cultivo del género, es decir, la incidencia del contexto colombiano como acontecimiento que actúa sobre el campo literario. La realidad de nuestro país nos sorprende a diario con sucesos fuera de alguna lógica que permita pensarlos coherentemente, sucesos que se desbordan, alimentando un sentido común hiperbolizado: la violencia y el conflicto, los desajustes estructurales que producen pobreza y desempleo, y al mismo tiempo, la dinámica de un país donde coexisten idiosincrasias, grupos humanos, ideologías, topografías, todos ellos radicalmente opuestos, muchos de ellos hasta el punto de la agresión mutua. Estas condiciones harán necesaria la aparición de nuevas formas de construcción simbólica. Una de ella es la novela negra. Y aunque cada escritor actualiza dicho espacio de sucesos con sus propias aproximaciones, la confluencia de muchos de ellos en este género es la que da lugar a la hipótesis de investigación sobre la presencia del mismo en nuestro medio como tendencia.

En conclusión, si hay algo que caracterice a la Nueva Novela Negra en nuestro país es la intención de hacer crítica social sin abandonar los caminos de la expresión artística: denunciar sin renunciar al arte. La novela negra en Colombia es nueva, en la medida en que busca retomar el modelo del género para dar forma al sentimiento de nuestro tiempo: el desencanto frente a la crisis del mundo que nos rodea y que no parece tener salida. Asimismo, es nueva entendida desde una estética especial paródica que, al parecer, radica en un uso particular, conciente del lenguaje, a veces metaficcional, a veces intertextual, y siempre dialógico, en la evaluación crítica del mundo. De ahí que pueda decirse que siendo un género de escape, resulta antiescapista, en tanto que puede relacionarse con la novela social, por el fuerte componente de malestar, de frustración social y de violencia que incorpora; y sin embargo, se mantiene profundamente irónico y carnavalesco en la reinvención de la parodia:

Vivimos en una era post-industrial donde la novela negra es un testigo descarnado de las cloacas que mueven el mundo, más allá del agente moralizador de la burguesía que acampaba en 
las páginas de las novelasenigma tradicionales. Los tiempos han cambiado y no hay retorno posible. El realismo y la denuncia imponen su rostro literario. Los mejores personajes de la novela negra actual son malas personas, pero, como diría Orwell, algunas son más malas que otras. (Sánchez Soler: 2003).

\section{Bibliografía}

Link, Daniel. (2003). El juego de los cautos. Literatura policial: de Edgar Allan Poe a P. D. James. Buenos Aires: La Marca.

Giardinelli, Tempo. (1980). "Coincidencias y divergencias en la li-teratura negra. (Apuntes para una explicación de las relaciones de la novela latinoamericana con la norteamericana del género policial)", en Revista Mexicana de Ciencias Sociales, No. 400, pp. 125-142.

Jacovkis, Natalia. (2006). "La ciudad neoliberal en la novela negra argentina: Puerto Apache, de Juan Martín", en Ciberletras, No. 15, disponible en http://www.lehman.cuny.edu/ciberletras/index.html

Paz Balibrea, Mari. (2002). "La novela negra en la transición española como fenómeno cultural: una interpretación”, en Iberoamericana. América Latina, España, Portugal: Ensayos sobre letras, historia y sociedad. Notas. Reseñas iberoamericanas, № 7, pp. 111- 118.

Prada Silva, Olga. (2005). Significación e importancia de la novela negra "Luna caliente" de Mempo Giardinelli. Tesis para optar al título de Magíster en Literatura, Pontificia Universidad Javeriana, Bogotá.

Pöppel, Hubert. (2001). La novela policíaca en Colombia. Medellín: Editorial Universidad de Antioquia,

Piglia, Ricardo. (2003). "Lo negro del policial", en El juego de los cautos. Literatura policial de Edgar Allan Poe a P. D. James. Buenos Aires: La Marca.

Pino, Miriam. (Abril de 2002). "El relato policial en América Latina", disponible en http://www.letrasdechile.cl/mambo/index.php. Encuentro de Narrativa Policial Latinoamericana. Chile, pp. 1-5.

Rainov, Bogomil. (1978). La novela negra. La Habana: Editorial Arte y Literatura.

Sánchez Soler, Mariano. (2003). Cómo se escribe una novela negra (¿se puede freír un huevo sin romperlo?). Alicante: Biblioteca Virtual Miguel de Cervantes. Disponible en http://www.cervantesvirtual.com/ FichaObra.html?Ref $=11444$

Silva, Juan Manuel. (2003). "Problemas y perspectivas del modelo crítico y su relación con la novela colombiana", en Revista Fundación Universitaria del Área Andina, No. 3 (agosto-diciembre). 